\title{
Meteor smoke influences on the D-region charge balance - review of recent in situ measurements and one-dimensional model results
}

\author{
C. Baumann ${ }^{1}$, M. Rapp ${ }^{1, *}$, A. Kero ${ }^{2}$, and C.-F. Enell ${ }^{2, * *}$ \\ ${ }^{1}$ Deutsches Zentrum für Luft- und Raumfahrt, Institut für Physik der Atmosphäre, Oberpfaffenhofen, Germany \\ ${ }^{2}$ Sodankylä Geophysical Observatory, University of Oulu, Tähteläntie 62, 99600, Sodankylä, Finland \\ *also at: Meteorologisches Institut München, Ludwig-Maximilians-Universität München, Munich, Germany \\ ** on leave to: EISCAT Scientific Association, Kiruna, Sweden
}

Correspondence to: C. Baumann (carsten.baumann@dlr.de)

Received: 9 August 2013 - Revised: 14 October 2013 - Accepted: 16 October 2013 - Published: 21 November 2013

\begin{abstract}
This work investigates the influence of meteoric smoke particles (MSP) on the charge balance in the D-region ionosphere. Both experimental in situ measurements and a one-dimensional ionospheric model reveal a clear impact of MSP on the ionospheric composition of the D-region. The study reviews rocket-borne in situ measurements of electron and positive ion density, which show a distinct deficit of electrons in comparison to positive ions between 80 and $95 \mathrm{~km}$. This deficit can be explained by the ambient negatively charged MSP measured simultaneously with a Faraday cup. The influence of MSP on the D-region charge balance is addressed with a simplified ionospheric model with only six components, i.e. electrons, positive and negative ions and neutral and charged MSP (both signs). The scheme includes reactions of plasma captured by MSP and MSP photo reactions as well as the standard ionospheric processes, e.g. ionion recombination. The model shows that the capture of plasma constituents by MSP is an important process leading to scavenging of electrons. Since Faraday cup measurements are biased towards heavy MSP because of aerodynamical filtering, we have applied an estimate of this filter on the modelled MSP densities. By doing that, we find good qualitative agreement between the experimental data and our model results. In addition, the model study reveals an increase of positive ions in the presence of MSP. That is primarily caused by the reduced dissociative recombination with electrons which have been removed from the gas phase by the MSP.
\end{abstract}

Keywords. Atmospheric composition and structure (aerosols and particles, middle atmosphere - composition and chemistry) - Ionosphere (ion chemistry and composition)

\section{Introduction}

Impacts of meteors on the Earth's atmosphere occur continuously and can be monitored by optical and radio methods. These observations show that the total meteoric mass influx, on an annual timescale, is dominated by the impact of small particles $(d \leq 100 \mu \mathrm{m})($ Ceplecha et al., 1998). Nearly all small meteors evaporate in the height region of 70-120 km (e.g. Stober et al., 2013, and references therein) and deposit material in that height regime. Rosinski and Snow (1961) and later Hunten et al. (1980) suggested that this meteoric material might at least partly recondense to form so-called meteor smoke particles (MSP). Experimental evidence for the existence of MSP comes from in situ measurements by sounding rockets (e.g. Schulte and Arnold, 1992; Gelinas et al., 1998; Lynch et al., 2005; Rapp et al., 2005, 2011), ground-based measurements with radar (Rapp et al., 2007; Strelnikova et al., 2009; Fentzke et al., 2009) and satellite observations (Hervig et al., 2009). There are also indications that the existence of this meteoric dust influences plasma measurements by triboelectric charging of the rocket payload (Barjatya and Swenson, 2006).

Today, MSP are thought to be involved in a large variety of atmospheric processes. For instance, it is commonly assumed that MSP act as nuclei for mesospheric ice clouds, leading 
to the phenomenon of polar mesospheric clouds or noctilucent clouds (e.g. Turco et al., 1982; Rapp and Thomas, 2006; Hervig et al., 2012). Furthermore it is considered that MSP influence the plasma of the D-region ionosphere and might be involved in creating so-called polar mesospheric winter echoes (see e.g. Havnes et al., 2011).

The part of the ionosphere with the most complex ion chemistry is the D-region. In this altitude region from 60$100 \mathrm{~km}$ the ionosphere does not consist of electrons, atomic and simple molecular positive ions alone. The ion composition is much more diverse, complex molecular ions and cluster ions can exist and both positive as well as negative ions do occur and can even coexist at some altitudes (e.g. Viggiano and Arnold, 1995). In this still not fully understood region we have identified MSP to be an important constituent for the conservation of quasineutrality within the ionosphere.

A loss of electrons due to scavenging by MSP, especially during nighttime, has been identified by Friedrich et al. (2012) using simultaneous electron and positive ion density measurements on sounding rockets. Our study addresses this influence on the D-region charge balance by reexamining in situ measurements of the MSP charge number density and the plasma measurements (Sect. 2). In addition, we present a one-dimensional ionospheric model that includes six components: electrons, positive ions, negative ions, as well as neutral, positively and negatively charged MSP (in Sect. 3). Besides the standard ionospheric reactions such as ionization $(Q)$, dissociative recombination $(\alpha)$ and ion-ion recombination $(\beta)$ we also consider MSP plasma capture reactions and MSP photo reactions in this one-dimensional ionospheric model. Using this very simple reaction scheme we can readily reproduce the observed electron loss due to the presence of MSP at nighttime (Sect. 3.3).

\section{Charged MSP signatures in rocket-borne measurements}

The first signatures of charged MSP were found by Schulte and Arnold (1992). To the best of our knowledge this is also the first detection of MSP at all. They used a quadrupole mass spectrometer mounted on a sounding rocket. In an integral mode, the mass spectrometer counted significant numbers of heavy negative ions above $400 \mathrm{amu}$ in an altitude range between $78-90 \mathrm{~km}$. Based on these results Schulte and Arnold (1992) suggested that these ions were actually negatively charged MSP.

The next major step in the investigation of charged aerosol particles in the mesopause region was taken by Havnes et al. (1996) who were the first to use a Faraday cup to measure charged ice particles inside radar returns from the vicinity of mesospheric ice clouds, also known as polar mesospheric summer echoes (e.g. Rapp and Lübken, 2004). This technique uses biased entrance grids to shield the electrode at

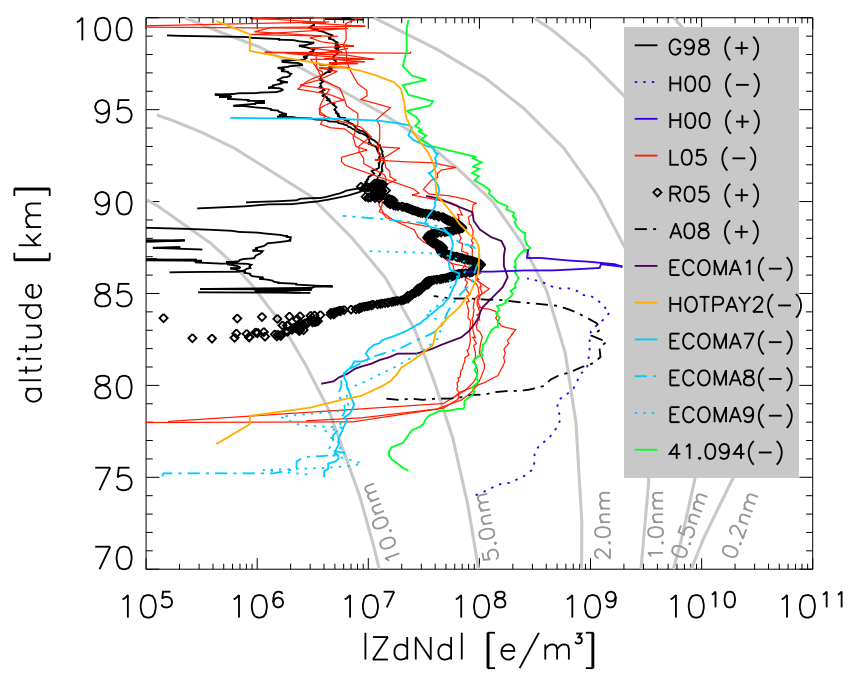

Fig. 1. Rocket-borne charged MSP density measurements during nighttime, updated from Rapp et al. (2007) and Friedrich and Rapp (2009), grey contours show MSP number densities after Hunten et al. (1980), legend entries are explained in Table 1, +/- indicate the charge sign of the measured MSP.

the bottom of the Faraday cup from ambient light ions and electrons and only allows "heavily" charged particles to be measured.

In this study we concentrate on the Faraday cup measurements and corresponding plasma observations on the same sounding rocket (see Table 1 for details of the rocket flights). These listed flights took mainly place at winter polar latitudes during nighttime. Gelinas et al. (1998) were the first to use this device during dark conditions outside the polar summer mesopause where ice particles occur. A further developed version of this MSP detector, which can distinguish between positive and negative charge, was later flown in 2002 and 2008 (Lynch et al., 2005; Rapp et al., 2005; Enell et al., 2011; Friedrich et al., 2012). Lately, the technique of the Faraday cup MSP detection has been combined with active photoionization by a xenon flash lamp (Rapp and Strelnikova, 2009; Strelnikova et al., 2009; Rapp et al., 2010, 2012) and was flown several times.

Additionally, Table 1 lists experiments that differ slightly from the original detector design. The probes from Horanyi et al. (2000) and Amyx et al. (2008) use magnetic instead of electrostatic fields to avoid contamination from ambient plasma. The MASS experiment (see Robertson et al., 2009, 2013, for details) on the other hand is a simple aerosol mass spectrometer. This, however, does not use active pumps like in the original Schulte and Arnold (1992) measurements and gives results comparable to Faraday cup observations, when only considering the 500-2000 amu mass channel (data taken from Friedrich et al., 2012).

In Fig. 1 all MSP height profiles of the experiments discussed briefly above are shown. We note that most of the 
Table 1. Collection of in situ measurements of charged MSP during darkness; the labels are used for the MSP height profiles in Fig. 1, the last five flights measured plasma densities simultaneously, mean values are shown in Fig. 2.

\begin{tabular}{lclll}
\hline Label & Lat. $\left({ }^{\circ} \mathrm{N}\right)$ & Date & Technique/Comments & Reference \\
\hline G98 & 18 & 19 February 1998 & Faraday cup & Gelinas et al. (1998) \\
H00 & 32 & 2 November 1998 & Magnetically shielded probe & Horanyi et al. (2000) \\
L05 & 65 & $\begin{array}{l}\text { 7 March 2002 } \\
\text { 15 March 2002 }\end{array}$ & $\begin{array}{l}\text { Faraday cup, } \\
\text { Four rocket flights }\end{array}$ & Lynch et al. (2005) \\
R05 & 68 & 28 October 2004 & Faraday cup & Rapp et al. (2005) \\
A08 & 69 & 10 January 2006 & Magnetically shielded probe & Amyx et al. (2008) \\
ECOMA1 & 69 & 8 September 2006 & Faraday cup & Strelnikova et al. (2009) \\
HOTPAY2 & 69 & 31 January 2008 & Faraday cup & Friedrich et al. (2012) \\
ECOMA7 & 69 & 4 December 2010 & Faraday cup & Rapp et al. (2012) \\
ECOMA8 & 69 & 13 December 2010 & Faraday cup & Rapp et al. (2012) \\
ECOMA9 & 69 & 19 December 2010 & Faraday cup & Rapp et al. (2012) \\
41.094 & 69 & 11 October 2011 & Aerosol spectrometer(MASS), & Robertson et al. (2013), \\
& & & 500-2000 amu channel & Friedrich et al. (2012) \\
\hline
\end{tabular}

measurements gave evidence for negatively charged particles. Note, however, that this does not necessarily mean that only negatively charged particles exist during darkness. Robertson et al. (2009) showed with the MASS experiment, that negatively and positively charged particles coexist. The character of Faraday cup measurements is that the sum of all detectable positively and negatively charged MSP is recorded (i.e. the net charge density). That means the measurement of a negative signal shows that an excess of negative MSP compared to positive MSP exists. The predominant negative charge of MSP is likely caused by the fact that the capture rate of plasma constituents by aerosol particles is proportional to $\sqrt{\frac{k T}{m}}$, which means that the mass of the plasma constituent is important. Since electrons are much lighter than ions, this results in a higher capture rate for electrons compared to positive ions. During nighttime, photoionization of neutral MSP by scattered Ly- $\alpha$ radiation from the geocorona (e.g. Meier, 1991, and references therein) as an additional source of positively charged MSP is possible, but not expected to be dominant.

Another interesting point is the peak charge number density of several $10^{8} \mathrm{e} \mathrm{m}^{-3}$ which are measured between 85 and $90 \mathrm{~km}$. These values are comparable to the electron densities in this altitude region. Taking into account that the Faraday cup measurements underlie aerodynamical filtering (Hedin et al., 2007; Strelnikova et al., 2009) it is possible that in some cases the real negative MSP density even outnumbers the electron density.

To support the speculation that MSP have an influence on the D-region charge balance, we refer to simultaneous measurements of electron and positive ion density from Friedrich et al. (2012). These measurements were conducted during the last five rocket flights listed in Table 1. The electron densities were measured by the radio wave propagation method, while a fixed biased DC-probe (positive ion probe - PIP) was used to quantify the positive ion density
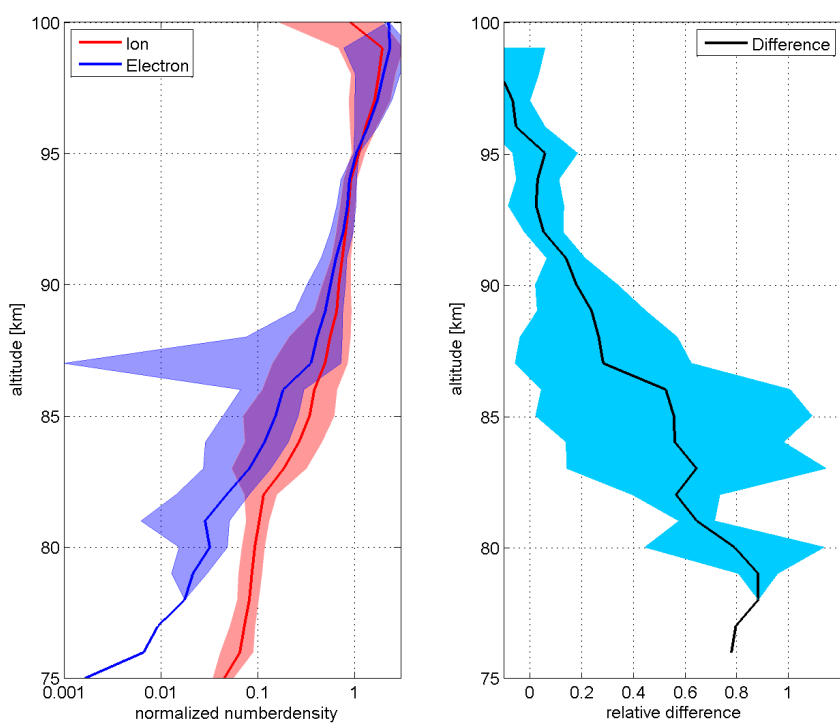

Fig. 2. Left panel: mean normalized electron density (black) and positive ion density (red) profiles from in situ measurements of Friedrich et al. (2012) with the corresponding standard deviation, the electron density at $95 \mathrm{~km}$ for each rocket flight has been used for normalization of electron and ion density. The standard deviation of the normalized electron densities exceeds the mean value at $88 \mathrm{~km}$. Right panel: relative difference between electron and positive ion density.

(e.g. Mechtly et al., 1967; Friedrich et al., 2013). Due to different levels of Ly- $\alpha$ ionisation the plasma densities differ in some cases by up to one order of magnitude. In order to be able to better interpret these five data sets and to demonstrate the robustness of the deviation from local charge neutrality due to the presence of MSP, we normalize the corresponding plasma densities. This means, we divide all plasma measurements by the corresponding electron density value measured at $95 \mathrm{~km}$. We show the mean values of electron 
and positive ion density together with their standard deviation in the left panel of Fig. 2 and the relative difference between electron and positive ion density in the right panel of Fig. 2. The variability of the electron and ion profiles (indicated by the shaded area around the means) is very large down to $\sim 80 \mathrm{~km}$, i.e. the standard deviation of both quantities overlap. Nevertheless, there is a significant difference between the electron and positive ion densities below $\sim 85 \mathrm{~km}$. This is clearly seen in the right panel of Fig. 2, which shows the relative difference between both quantities, e.g. the difference between the normalized number densities relative to the normalized ion density $\left(\left(N_{\mathrm{I}}^{\mathrm{R}}-N_{\mathrm{e}}^{\mathrm{R}}\right) / N_{\mathrm{I}}^{\mathrm{R}}\right.$, the R stands for relative), along with its standard deviation.

In the Earth's D-region ionosphere the concept of quasineutrality is generally valid, i.e. the sum of all charges in a volume larger than a Debye-sphere is zero. In Fig. 2 (left panel) this quasineutrality is obvious above $95 \mathrm{~km}$, where electron and positive ion density are the same. However, below $95 \mathrm{~km}$ quasineutrality is obviously no longer maintained by electrons and positive ions alone. Other negative charge carriers have to be considered below this altitude in addition to electrons. As a first guess negative ions could possibly be this negative charge carrier. However, it is well known that negative ions are destroyed by reaction with atomic oxygen (e.g. Turunen et al., 1996) down to $\sim 80 \mathrm{~km}$ and a significant atomic oxygen density is regularly observed above $\sim 80 \mathrm{~km}$ by satellite, airglow and sounding rocket measurements (e.g. Russel et al., 2005; Friedrich et al., 2012). Therefore the negative ions can only explain the measured deviation between electron and positive ion density below $\sim 80 \mathrm{~km}$. In between $\sim 80 \mathrm{~km}$ and $95 \mathrm{~km}$ there must be another negative charge carrier to conserve quasineutrality. And indeed, we find negatively charged MSP in this altitude range (Fig. 1). In the following we want to check the assumption of Friedrich et al. (2012) that MSP are a sink for electrons. We do that by applying a simple ionospheric model where we include MSP as active constituents. The model and some initial results are described in the following sections.

\section{Model study of the charge balance of MSP}

\subsection{Model description}

Recent ionospheric models concerning the D-region, such as the Sodankylä Ion and neutrals Chemistry (SIC) model (Turunen et al., 1996), do not consider MSP in their calculations. As described above, however there is strong experimental evidence for MSP influence on the D-region charge balance. Because of this, we present a simple ionospheric model, which also covers MSP, for the altitude region 60$100 \mathrm{~km}$. This model includes six species: electrons, positive ions, negative ions, neutral MSP, positive MSP and negative MSP. We note that using only six species means a significant idealization of the very complex D-region ion chem- istry. However, the reaction rates and masses of molecular and cluster ions are still very different from the corresponding mass and reaction rates of MSP. Hence it appears warranted to categorize the various plasma species into electrons, positive ions and negative ions and MSP in order to study the qualitative effect of MSP on the partitioning of charge between these various species.

The reaction scheme for all six components includes thirteen different reactions overall. In the following chemical reactions $P, P_{\mathrm{p}}$ and $P_{\mathrm{n}}$ denote neutral, positive, and negative MSP, respectively, while $e^{-}, I^{+}$and $I^{-}$represent electrons, positive ions and negative ions, respectively. These reactions can be divided into three different groups. The first group describes the ionospheric background covering standard plasma reactions, e.g. like the electron-ion pair production rate $Q$. The reaction rate coefficients $k_{1}^{\mathrm{S}}-k_{5}^{\mathrm{S}}$ are taken from the SIC model, which is - to our knowledge - one of the currently most advanced D-region models.

$$
\begin{aligned}
& (M+h v) \stackrel{k_{1}^{\mathrm{S}}}{\rightarrow} e^{-}+I^{+} \\
& e^{-}+I^{+} \stackrel{k_{2}^{\mathrm{S}}}{\rightarrow}(M) \\
& e^{-}(+M) \stackrel{k_{3}^{\mathrm{S}}}{\rightarrow} I^{-}(+M) \\
& I^{-}(+M / h v) \stackrel{k_{4}^{\mathrm{S}}}{\rightarrow} e^{-}(+M) \\
& I^{+}+I^{-} \stackrel{k_{5}^{\mathrm{S}}}{\rightarrow}(M)
\end{aligned}
$$

The reaction rate coefficient $k_{1}^{\mathrm{S}}, k_{3}^{\mathrm{S}}$ and $k_{4}^{\mathrm{S}}$ are already multiplied by the corresponding neutral densities $(M)$ since the simple model does not consider neutral constituents in its calculations. In addition, it has to be noted that $k_{4}^{\mathrm{S}}$ describes the combination of photo detachment and collisional detachment of electrons from negative ions. The combination is carried out in the following way:

$k_{4}^{\mathrm{S}}=k_{\text {photo }}+k_{\text {col. }} \cdot[M]$.

Here $k_{\text {photo }}$ is the photo detachment rate coefficient, $k_{\text {col. }}$ is the collisional detachment rate coefficient and $[M]$ denote the density of atomic oxygen, $\mathrm{H}_{2}, \mathrm{O}_{3}$, NO and other minor species colliding with the negative ions. Note that in the height region above $80 \mathrm{~km}$ the collision with atomic oxygen is the main sink for negative ions. The used atomic oxygen profile is derived within the SIC model which is shown in the right panel of Fig. 3. 
The second group of reactions are plasma capture reactions by MSP.

$$
\begin{gathered}
P+e^{-} \stackrel{k_{6}^{\mathrm{C}}}{\rightarrow} P_{\mathrm{n}} \\
P+I^{+} \stackrel{k_{7}^{\mathrm{C}}}{\rightarrow} P_{\mathrm{p}} \\
P_{\mathrm{n}}+I^{+} \stackrel{k_{8}^{\mathrm{C}}}{\rightarrow} P \\
P_{\mathrm{p}}+e^{-} \stackrel{k_{9}^{\mathrm{C}}}{\rightarrow} P \\
P+I^{-} \stackrel{k_{10}^{\mathrm{C}}}{\rightarrow} P_{\mathrm{n}} \\
P_{\mathrm{p}}+I^{-} \stackrel{k_{11}^{\mathrm{C}}}{\rightarrow} P
\end{gathered}
$$

Finally, the third group of reactions are MSP photo reactions which also occur during the nighttime due to Ly- $\alpha$ photons resonantly scattered by the geocorona.

$$
\begin{gathered}
P_{\mathrm{n}}+\frac{h \cdot c}{\lambda_{1}^{*}} \stackrel{k_{12}^{\mathrm{P}}}{\rightarrow} P+e^{-} \\
P+\frac{h \cdot c}{\lambda_{2}^{*}} \stackrel{k_{13}^{\mathrm{P}}}{\rightarrow} P_{\mathrm{p}}+e^{-}
\end{gathered}
$$

To start, Table 2 summarizes all relevant information about the 13 reaction rates used in this study. That is, the meaning of all reaction rate coefficients is specified, and their units together with the original references are given.

We use the output of the SIC-model for a realistic background ionosphere. SIC derives concentrations of 88 constituents, i.e. 44 positive ion species, 28 negative ion species and 16 neutral species. In Fig. 3 the density of important negative and positive ions in the D-region are shown. It has to be noted that the altitude range of the SIC model is 20 $150 \mathrm{~km}$, but in this study we focus on the region between $60-100 \mathrm{~km}$ where significant number densities of MSP exist (e.g. Hunten et al., 1980).

As stated above, the SIC model simulates the number density of several positive ions, negative ions and minor neutrals. As input, the SIC model uses the background neutral atmosphere from the MSISE-90 model (Hedin, 1991) and a solar spectrum from the Solar Irradiance Platform (former Solar 2000 (Tobiska et al., 2000)). The electron density $N_{\mathrm{e}}$ is deduced from the difference between the sum of all positive ions $\left(N_{I^{+}}\right)$and the sum of all negative ions $\left(N_{I^{-}}\right)$.

$N_{\mathrm{e}}=N_{I^{+}}-N_{I^{-}}$

The SIC model uses many different ion reactions, which we have summarized in the reaction rate coefficients $k_{1}^{\mathrm{S}}-k_{5}^{\mathrm{S}} \cdot k_{1}^{\mathrm{S}}$ represents the ionization of neutrals by solar radiation and galactic cosmic rays, i.e. quiet-day conditions. Electron and proton precipitation, caused by solar proton events or coronal mass ejections, can increase the ionization levels of the D-region by two orders of magnitude, but are not believed to change the qualitative correctness of our results. The generalization of reaction rate coefficients $k_{2}^{\mathrm{S}}-k_{5}^{\mathrm{S}}$ has been done
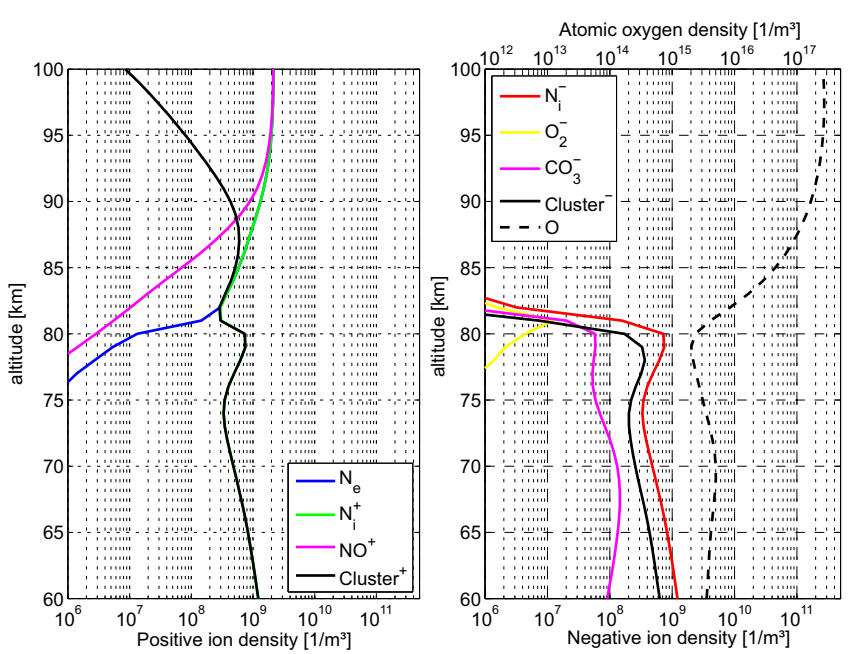

Fig. 3. Density profiles of selected positive ions and electrons (left) and density profiles of negative ions together with the atomic oxygen profile (right); Cluster ${ }^{+/-}$means the sum of all cluster ions, $\mathrm{N}_{i}^{+/-}$denotes the sum of all ions, for 8th September 2010, 23:55 LT, $69^{\circ} \mathrm{N}, 16^{\circ} \mathrm{E}$.

by taking the means of all corresponding single ion reactions in the SIC model, which has been weighted also by each ion density. The reactions rate coefficients $k_{2}^{\mathrm{S}}, k_{3}^{\mathrm{S}}$ and the collisional part of $k_{4}^{\mathrm{S}}$ are multiplied by the neutral densities corresponding to each chemical reaction in SIC. For $k_{4}^{\mathrm{S}}$ this is mainly atomic oxygen, together with some minor constituents like $\mathrm{H}_{2}, \mathrm{O}_{3}$ and NO. It has to be noted that the generalization of the electron - positive ion recombination for molecular and cluster ions, which differ significantly, might be inappropriate. As seen in Fig. 3, however, the transition region between the molecular ion regime and the cluster ion regime is vertically very isolated around $85 \mathrm{~km}$.

The SIC model has been run for a geographical location of $69^{\circ} \mathrm{N}$ and $16^{\circ} \mathrm{E}$ (Andenes, Norway), since most of the rocket flights were conducted from there. The time frame of the SIC run was set somewhat arbitrarily to the 8 September 2010, because there are partly sunlit and dark conditions during the same day and because one of the rocket flights, ECOMA01 (see the MSP profile Fig. 1), was conducted on this day of the year. Since SIC is a time-dependent model intended for studying short-lived ionization events, such as energetic particle precipitation, it is standard practice to set it up for a certain date and location by running a full $24 \mathrm{~h}$ cycle with only sunlight and cosmic rays as ionization sources. This is repeated several times until a quasi-steady state is reached. Since rocket measurements observe variations of the electron density during the nighttime of up to two orders of magnitude (e.g. Friedrich et al., 2012), there have to be sources of additional ionization during quiet ionospheric conditions at polar latitudes. This is most likely electron and proton precipitation from the radiation belts, which is also directly linked to the solar activity. In order to provide a quantitative assessment 
Table 2. Description of the thirteen reaction rate coefficients, their units in the model and reference of their origin.

\begin{tabular}{llll}
\hline$k_{\mathrm{n}}$ & Unit & Comment & Reference \\
\hline$k_{1}^{\mathrm{S}}$ & $\mathrm{m}^{-3} \mathrm{~s}^{-1}$ & ionization & SIC res.: Turunen et al. (1996) \\
$k_{2}^{\mathrm{S}}$ & $\mathrm{m}^{3} \mathrm{~s}^{-1}$ & dissociative recomb. & SIC res.: Turunen et al. (1996) \\
$k_{3}^{\mathrm{S}}$ & $\mathrm{s}^{-1}$ & electron attach. to neutrals & SIC res.: Turunen et al. (1996) \\
$k_{4}^{\mathrm{S}}$ & $\mathrm{s}^{-1}$ & electron detach. from neg. ions. & SIC res.: Turunen et al. (1996) \\
$k_{5}^{\mathrm{S}}$ & $\mathrm{m}^{3} \mathrm{~s}^{-1}$ & ion-ion recomb. & SIC res.: Arijs et al. (1987) \\
$k_{6}^{\mathrm{C}}$ & $\mathrm{m}^{3} \mathrm{~s}^{-1}$ & electron attach. to MSP & Rapp (2000), Natanson (1960) \\
$k_{7}^{\mathrm{C}}$ & $\mathrm{m}^{3} \mathrm{~s}^{-1}$ & pos. ion attach. to MSP & Rapp (2000), Natanson (1960) \\
$k_{8}^{\mathrm{C}}$ & $\mathrm{m}^{3} \mathrm{~s}^{-1}$ & pos. ion attach. to MSP- & Rapp (2000), Natanson (1960) \\
$k_{9}^{\mathrm{C}}$ & $\mathrm{m}^{3} \mathrm{~s}^{-1}$ & electron attach. to MSP+ & Rapp (2000), Natanson (1960) \\
$k_{10}^{\mathrm{C}}$ & $\mathrm{m}^{3} \mathrm{~s}^{-1}$ & neg. ion attach. to MSP & Rapp (2000), Natanson (1960) \\
$k_{11}^{\mathrm{C}}$ & $\mathrm{m}^{3} \mathrm{~s}^{-1}$ & neg. ion attach. to MSP+ & Rapp (2000), Natanson (1960) \\
$k_{12}^{\mathrm{P}}$ & $\mathrm{s}^{-1}$ & MSP- electron detach. & Rapp (2009) \\
$k_{13}^{\mathrm{P}}$ & $\mathrm{s}^{-1}$ & MSP ionization & Rapp (2009) \\
\hline & & &
\end{tabular}
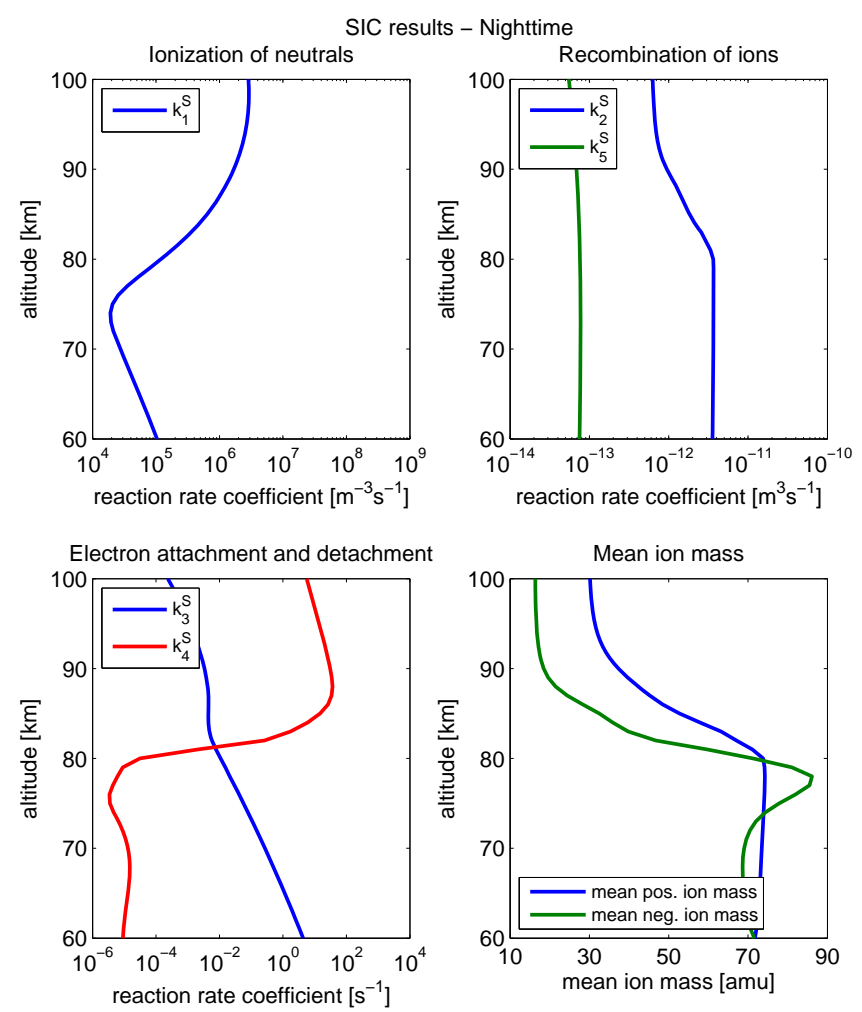

Fig. 4. Input reaction rate coefficients $k_{1}^{\mathrm{S}}-k_{5}^{\mathrm{S}}$ in the appropriate form for the use in the described model (see Table 2 for details), note $k_{1}^{\mathrm{S}}$ is the absolute ionization rate due to solar radiation and galactic cosmic rays; also shown is the mean ion mass, from SIC model results, for the 8th September $2010,23: 55 \mathrm{LT}, 69^{\circ} \mathrm{N}, 16^{\circ} \mathrm{E}$. of the error introduced by our assumption of a quiet ionosphere, additional simulations will be required which should be done in the future using the full SIC-model. In Fig. 4 we show output variables from this SIC model run which we will further use in the simple model containing MSP reactions below. Besides the reaction rate coefficients $k_{1}^{\mathrm{S}}-k_{5}^{\mathrm{S}}$. It is important to remark, that these reaction rate coefficients represent a quiet background ionosphere, which allows us to derive absolute number densities of all six modelled constituents in a qualitative manner. For a quantitative comparison with measurements more realistic profiles of the ionization rate, etc., would be required - corresponding information is, however, not available. Finally, we take the altitude-dependent mean ion mass from SIC, which enters the expressions for the various ion-capturing processes by MSP (see Eqs. 2 and 4).

The plasma-capturing reactions of MSP (see Eqs. R6R11) were reexamined by Rapp (2000) for use in the mesosphere. Originally, these equations were presented by Natanson (1960). In general, this theory provides capture rates for all conceivable combinations of aerosol and ion/electron charges. Here we only consider the attractive case (plasma captured by oppositely charged MSP) and the neutral case (plasma captured by neutral MSP) and neglect the repulsive case. This is a reasonable simplification for the case of MSP, whose size is so small that multiply charged particles can basically not occur (e.g. Rapp and Lübken, 2001). The following equation describes the charging of neutral MSP by electrons, positive ions and negative ions.

$$
\begin{aligned}
k_{6 / 7 / 10}^{\mathrm{C}}= & \gamma_{\text {charging }} \cdot \pi \cdot r_{\mathrm{p}}^{2} \cdot c_{\mathrm{e}^{-} / I^{+} / I^{-}} \\
& \cdot\left(1+\sqrt{\frac{e^{2}}{8 \cdot \epsilon_{0} \cdot k \cdot T_{\mathrm{e}^{-} / I^{+} / I^{-}} \cdot r_{\mathrm{p}}}}\right)
\end{aligned}
$$


Here, $r_{\mathrm{p}}$ is the MSP radius, $c_{\mathrm{e} / \mathrm{i}}$ is the thermal velocity of the electrons and ions respectively, $e$ is the elementary charge, $\epsilon_{0}$ is the permittivity of free space, $k$ is the Boltzmann constant and $T_{\mathrm{e} / \mathrm{i}}$ the electron and ion temperature, which are identical to the neutral temperature (from MSISE-90) in the D-region. The coefficient $\gamma_{\text {charging }}$ is a dimensionless quantity which describes the size-dependent probability of an MSP to capture a plasma constituent (Megner and Gumbel, 2009). For the value of $\gamma_{\text {charging }}$ we follow the arguments of Megner and Gumbel (2009), who assumed that the probability is zero for particles with radii smaller than $0.25 \mathrm{~nm}$ and the probability is one for particle radii larger than $1.5 \mathrm{~nm}$. In between they suggest a linear increase. We have adopted this treatment into our model, i.e. we define $\gamma_{\text {charging }}$ as follows:

$\gamma_{\text {charging }}\left(r_{\mathrm{p}}\right)= \begin{cases}0, & \text { for } r_{\mathrm{p}}<0.25 \mathrm{~nm}, \\ 0.8 \cdot r_{\mathrm{p}}-0.2, & \text { for } 0.25 \leq r_{\mathrm{p}} \leq 1.5 \mathrm{~nm},(3) \\ 1, & \text { for } r_{\mathrm{p}}>1 \mathrm{~nm} .\end{cases}$

For the attractive case, where a charged MSP captures an oppositely charged plasma constituent and recombines to a neutral MSP, we use Eq. (4), which is valid for a singly charged MSP.

$$
\begin{aligned}
k_{7 / 8 / 11}^{\mathrm{C}}= & \gamma_{\mathrm{recomb}} \cdot \pi \cdot r_{\mathrm{p}}^{2} \cdot c_{\mathrm{e}^{-} / I^{+} / I^{-}} \\
& \cdot\left(1+\frac{|q| \cdot e^{2}}{4 \cdot \pi \cdot \epsilon_{0} \cdot k \cdot T_{\mathrm{e}^{-} / I^{+} / I^{-}} \cdot r_{\mathrm{p}}}\right)
\end{aligned}
$$

For the recombination probability $\gamma_{\text {recomb }}$ we again follow the arguments of Megner and Gumbel (2009) and set $\gamma_{\text {recomb }}=1$.

MSP are also influenced by electromagnetic radiation of sufficiently short wavelengths (as discussed in the following) from X-rays and hard UV up to the visible range. Negatively charged MSP can lose an electron due to photo detachment and neutral MSP can be photo-ionized. In this study we concentrate on nighttime conditions. Therefore the sun does not play a significant role, but due to the hydrogen layer in the upper atmosphere (geocorona), solar Ly- $\alpha$ radiation is resonantly scattered from the sunlit side into the dark side of the Earth. Following Rapp (2009), the reaction rate coefficient for the photo reactions are derived using Mie theory, i.e.

$k_{12 / 13}^{\mathrm{P}}=\int_{\lambda_{0}}^{\lambda_{1 / 2}^{*}} F(\lambda, \chi) \cdot \sigma_{1 / 2}\left(r_{\mathrm{p}}, m, \lambda\right) \cdot \mathrm{d} \lambda$.

Here, $F(\lambda, \chi)$ is the wavelength and solar zenith dependent solar irradiance and $\sigma_{1 / 2}\left(r_{\mathrm{p}}, m, \lambda\right)$ the absorption cross section. The integral is taken over the wavelength from a starting point $\lambda_{0}$ to the wavelengths $\lambda_{1 / 2}^{*}$. In an ideal case $\lambda_{0}=0$, but since spectroscopic material data is only available in a limited wavelength region, we have chosen $\lambda_{0}$ to be $100 \mathrm{~nm}$. In any case, during the nighttime the most important light source is the Ly- $\alpha$ radiation scattered from the geocorona with a wavelength of $121.6 \mathrm{~nm}$. $\lambda_{1}^{*}$ corresponds to the lowest photon energy that can detach an electron from a negatively charged MSP (i.e. the electron affinity), while $\lambda_{2}^{*}$ corresponds to the lowest energy of a photon that can ionize neutral MSP (i.e. the work function). We follow the argumentation of Rapp et al. (2010) that $\lambda_{1}^{*}=2.2 \mathrm{eV}(\cong 560 \mathrm{~nm})$ and $\lambda_{2}^{*}=5.5 \mathrm{eV}(\cong 225 \mathrm{~nm})$. However, we want to indicate that these values are not very well known and are subject to major uncertainties. The solar irradiance is taken from the SIC model, which derives height resolved spectra. The cross section for photodetachment/photoemission is then given by the following equation using Mie theory:

$\sigma_{1 / 2}\left(r_{\mathrm{p}}, m, \lambda\right)=\pi r_{\mathrm{p}}^{2} \cdot Q_{\mathrm{abs}}\left(r_{\mathrm{p}}, m, \lambda\right) \cdot Y_{1 / 2}$.

The photo emission/detachment cross section is a function of MSP composition. This composition dependence is described by $Q_{\text {abs }}$. $Q_{\text {abs }}$ is the absorption efficiency in the Mie scattering theory and a function of the complex refractive index $m=n-i \cdot k$, where $n$ is the refractive index and $k$ is the absorption coefficient. To the authors' knowledge, $n-k$ data in the range from 100 to $600 \mathrm{~nm}$ exists only for hematite $\left(\mathrm{Fe}_{2} \mathrm{O}_{3}\right)$ as a reasonable MSP material (Triaud, 2013). Since MSP particles have sizes much smaller than $100 \mathrm{~nm}$, the Mie calculation can be approximated in the Rayleigh regime as follows (Eidhammer and Havnes, 2001):

$Q_{\mathrm{abs}}=4 X \frac{6 n k}{\left(n^{2}-k^{2}+1\right)^{2}+(2 n k)^{2}}$,

where $X=2 \pi r_{p} / \lambda$ denotes the Mie parameter from the Mie theory. In Eq. (6) the quantity $Y$ is the photoemission yield, which we have derived using the Fowler-Nordheim law (Fowler and Nordheim, 1928; Schmidt-Ott et al., 1980).

$Y_{1 / 2}(\lambda)=C\left(\phi_{1 / 2}-\frac{h \cdot c}{\lambda}\right)^{2}$

Here $\phi_{1 / 2}$ is the corresponding electron affinity/workfunction (photodetachment or photoionization) and $\mathrm{C}$ is a material constant which we set in our calculation to 0.01 (Schmidt-Ott et al., 1980).

In our ionospheric model we use the altitude-dependent MSP size distribution from Megner et al. (2006) (see Fig. 5). Therefore all the described MSP reaction rate coefficients are derived size and height dependent. By doing so we can make statements on the influence of MSP on the charge balance in altitude range between 60 and $100 \mathrm{~km}$. Due to the atmospheric circulation MSP are transported from the summer mesosphere to the winter stratosphere (Megner et al., 2008). As stated above, this study is considering September conditions motivated by the availability of MSP data. As it turns out, this time of the year is least sensitive to circulation effects such that the one-dimensional model results of Megner et al. (2006) can be used. For further study of different parts of the seasonal cycle it is necessary to use MSP 


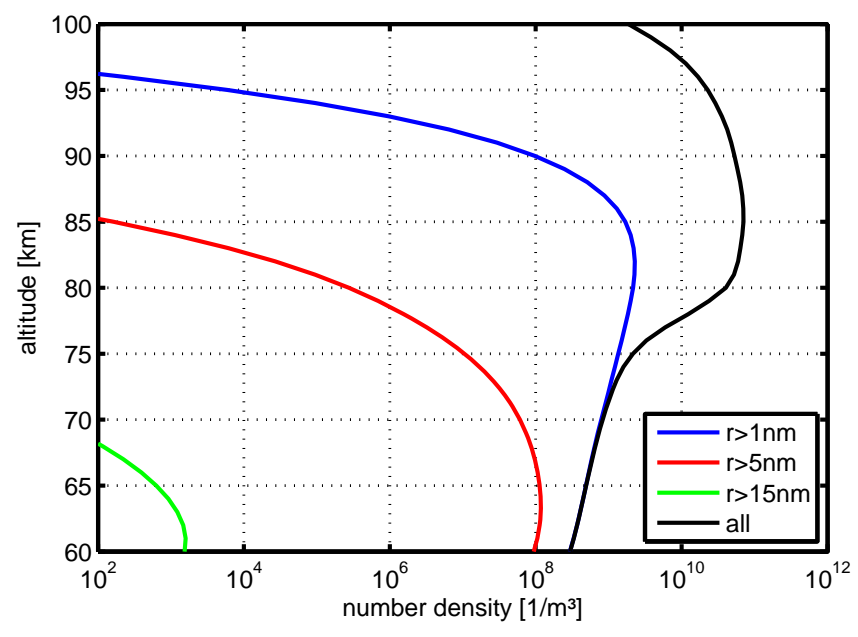

Fig. 5. Sum of MSP number densities for particle sizes greater than $1 \mathrm{~nm}$ (blue), $5 \mathrm{~nm}$ (red) and $15 \mathrm{~nm}$ (green) and all MSP (black), from the model of Megner et al. (2006).

distributions from Megner et al. (2008) to account for the meridional transport of MSP in the atmosphere. This will be done in future investigations.

The following rate equations for all six modelled constituents describe the reaction kinetics as treated in the model. The model itself solves these rate equations time dependently to reach a steady state by using the mathematical methods which are also used in the SIC model. The ion and electron densities in Fig. 3 and the neutral MSP densities for each size bin are used as initial values for the ionospheric model. The quantities in brackets denote the concentrations of the abovementioned six model constituents.

$$
\begin{aligned}
\frac{\partial\left[e^{-}\right]}{\partial t}= & k_{1}^{\mathrm{S}}+k_{4}^{\mathrm{S}}\left[I^{-}\right]+k_{12}^{\mathrm{P}}\left[P_{\mathrm{n}}\right]+k_{13}^{\mathrm{P}}[P]-k_{2}^{\mathrm{S}}\left[e^{-}\right]\left[I^{+}\right] \\
& -k_{3}^{\mathrm{S}}\left[e^{-}\right]-k_{6}^{\mathrm{C}}[P]\left[e^{-}\right]-k_{9}^{\mathrm{C}}\left[P_{\mathrm{p}}\right]\left[e^{-}\right]
\end{aligned}
$$

$$
\begin{aligned}
\frac{\partial\left[I^{+}\right]}{\partial t}= & k_{1}^{\mathrm{S}}-k_{2}^{\mathrm{S}}\left[e^{-}\right]\left[I^{+}\right]-k_{7}^{\mathrm{C}}[P]\left[I^{+}\right]-k_{8}^{\mathrm{C}}\left[P_{\mathrm{n}}\right]\left[I^{+}\right] \\
& -k_{5}^{\mathrm{S}}\left[I^{+}\right]\left[I^{-}\right]
\end{aligned}
$$

$$
\begin{aligned}
\frac{\partial\left[I^{-}\right]}{\partial t}= & k_{3}^{\mathrm{S}}\left[e^{-}\right]-k_{4}^{\mathrm{S}}\left[N_{i} n\right]-k_{10}^{\mathrm{C}}[P]\left[I^{-}\right]-k_{11}^{\mathrm{C}}\left[P_{\mathrm{p}}\right]\left[I^{-}\right] \\
& -k_{5}^{\mathrm{S}}\left[I^{+}\right]\left[I^{-}\right]
\end{aligned}
$$

$$
\begin{aligned}
\frac{\partial[P]}{\partial t}= & k_{8}^{\mathrm{C}}\left[P_{\mathrm{n}}\right]\left[I^{+}\right]+k_{9}^{\mathrm{C}}\left[P_{\mathrm{p}}\right]\left[e^{-}\right]+k_{12}^{\mathrm{P}}\left[P_{\mathrm{n}}\right]+k_{11}^{\mathrm{C}}\left[P_{\mathrm{p}}\right]\left[I^{-}\right] \\
& -k_{6}^{\mathrm{C}}\left[e^{-}\right][P]-k_{7}^{\mathrm{C}}\left[I^{+}\right][P]-k_{13}^{\mathrm{P}}[P]-k_{10}^{\mathrm{C}}[P]\left[I^{-}\right]
\end{aligned}
$$

$$
\frac{\partial\left[P_{\mathrm{p}}\right]}{\partial t}=k_{7}^{\mathrm{C}}\left[I^{+}\right][P]+k_{13}^{\mathrm{P}}[P]-k_{9}^{\mathrm{C}}\left[P_{\mathrm{p}}\right]\left[e^{-}\right]-k_{11}^{\mathrm{C}}\left[P_{\mathrm{p}}\right]\left[I^{-}\right]
$$

$$
\frac{\partial\left[P_{\mathrm{n}}\right]}{\partial t}=k_{6}^{\mathrm{C}}\left[e^{-}\right][P]+k_{10}^{\mathrm{C}}[P]\left[I^{-}\right]-k_{8}^{\mathrm{C}}\left[P_{\mathrm{n}}\right]\left[I^{+}\right]-k_{12}^{\mathrm{P}}\left[P_{\mathrm{n}}\right] .
$$

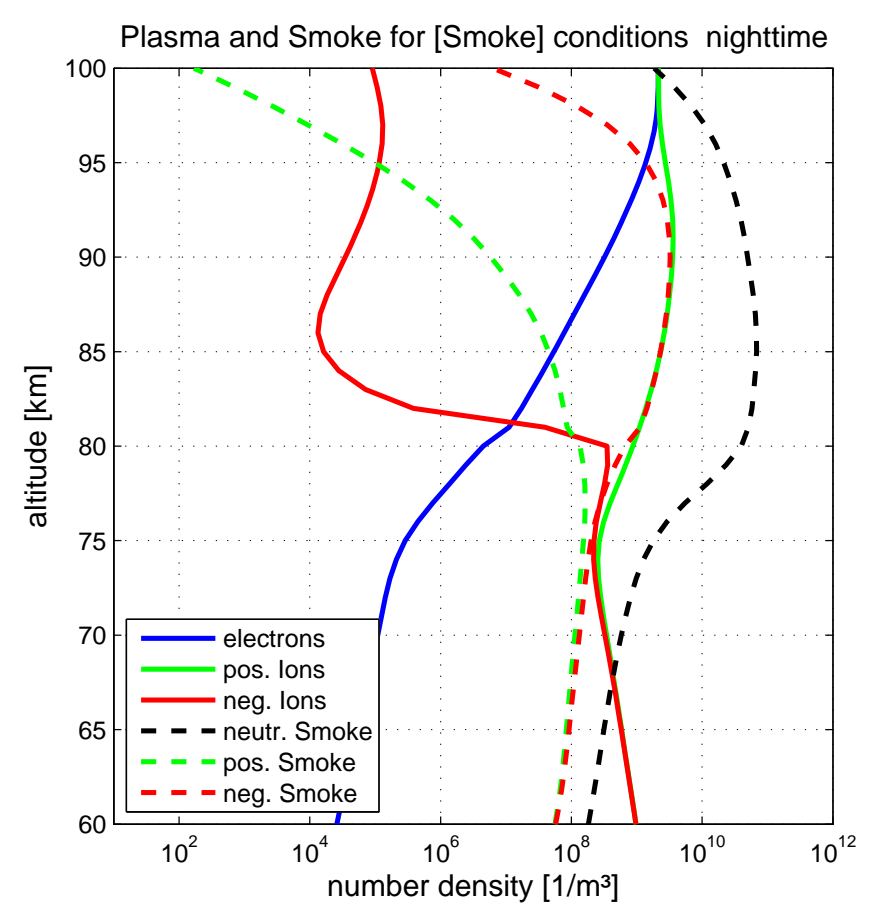

Fig. 6. Height profiles of the six modelled species, electrons, positive ions, negative ions, neutral MSP, positive MSP and negative MSP.

In the next section we present MSP model results for nighttime conditions in which the described in situ measurements have been made. Additionally, for the later analysis of the model results we compare the reaction rates corresponding to the production and loss processes of the rate Eqs. (9)(14) by using this nomenclature.

\subsection{Nighttime results}

In Sect. 2 we argued for an influence of MSP on the charge balance in the altitude region between 80 and $95 \mathrm{~km}$ based on the evidence from rocket-borne measurements. As a next step, these arguments will be tested with the simple ionospheric model including the MSP described above.

The geophysical conditions we have modelled here are for the 8 September at Andøya $\left(69^{\circ} \mathrm{N}, 16^{\circ} \mathrm{E}\right)$, which is identical to the ECOMA-01 flight (Strelnikova et al., 2009). As mentioned above, this date allows us to analyze day and night conditions, while we concentrate on the nighttime results in this study. Eqs. (9)-(14) are solved time dependently with the initial conditions as shown in Figs. 4 and 5.

Figure 6 shows altitude profiles for all considered species. In the altitude region between 80 and $95 \mathrm{~km}$ negatively charged MSP take over the role of electrons and balance the positive charge of the positive ions to achieve quasineutrality. This means that we can confirm the suggestion from rocket-borne observations that MSP have a significant influence on the charge balance in that height region. In addition, 


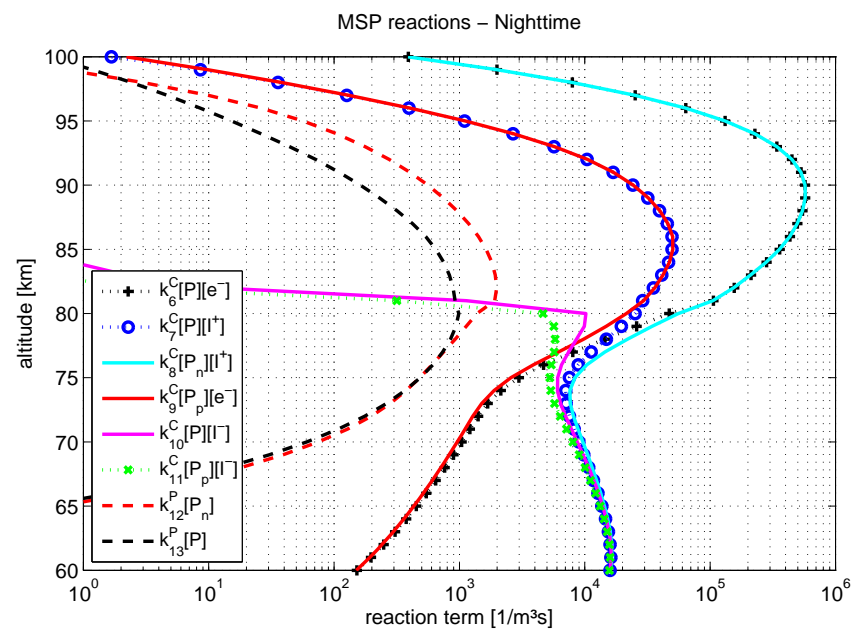

Fig. 7. Height profiles of MSP photoreaction rates (dashed lines) and plasma capture rates by MSP (solid lines); compare legend entries with Equations 12-14.

parallel to the negative MSP, there are also positive MSP at all modeled altitudes, but the concentration of the latter is much smaller down to $75 \mathrm{~km}$. Below that height negative and positive MSP surprisingly have the same densities. To interpret the results in Fig. 6, we show in Fig. 7 the MSP-related reaction terms as described in the rate Eqs.(12)-(14).

From Fig. 7, it is obvious that the neutral MSP capture rate of electrons is very important above $80 \mathrm{~km}$, i.e. electrons attach very rapidly to the neutral MSP. This process is balanced by positive-ion capture through negative MSP, i.e. the recombination rate of negative MSP with positive ions is equally fast. This happens despite the fact that the reaction rate coefficients of ions captured by MSP are much smaller compared to electron-capturing coefficients. This contradiction can be explained by the very high concentrations of negative MSP and positive ions as shown in Fig. 6. Due to the fact that there is no additional electron production process in the MSP height, there is hardly any importance of electrons for the conservation of the charge balance here.

Our model results also reveal that positively charged MSP can exist during the nighttime due to ion-capturing processes. Above $80 \mathrm{~km}$ the capture process of positive ions by neutral MSP is in balance with the capture of electrons by positively charged MSP. That leads to the substantial decrease of number densities of positively charged MSP in this altitude region (see Fig. 6) with peak number densities of $10^{8} \mathrm{~m}^{-3}$ at $\sim 80 \mathrm{~km}$. The photo reaction rates $k_{12}^{\mathrm{P}}\left[P_{\mathrm{n}}\right]$ and $k_{13}^{\mathrm{P}}[P]$ are not zero due to Ly- $\alpha$ from the geocorona, but compared to the capture rates they do not play a significant role.

Below $80 \mathrm{~km}$ the capture of negative ions by neutral and positively charged smoke is also possible. Between 75 and $80 \mathrm{~km}$ all capture processes of MSP lie within the same order of magnitude. Below $75 \mathrm{~km}$ the capture of electrons becomes insignificant and all rates for the capture of ions converge.
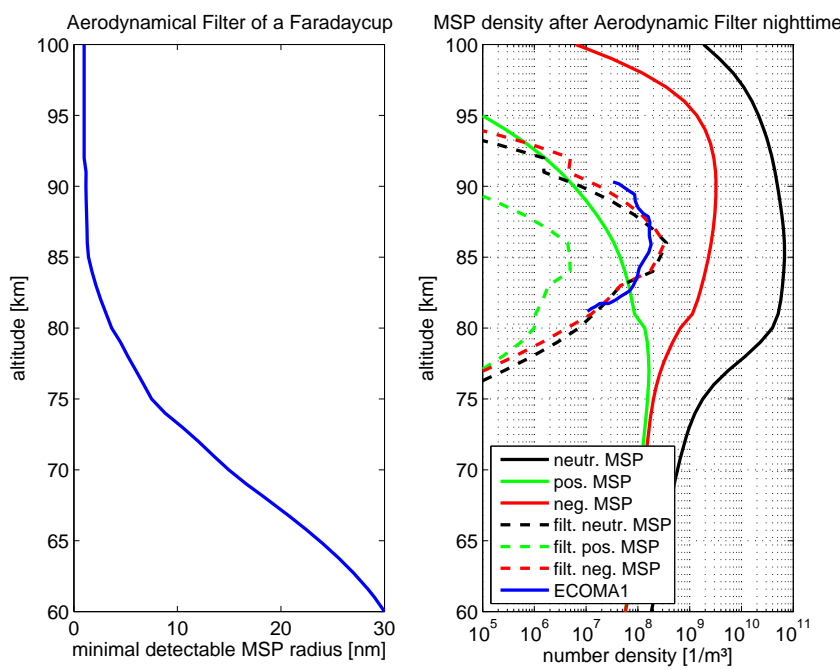

Fig. 8. Left panel: aerodynamical filter that applies to Faraday cup measurements of MSP with a rocket trajectory typical for previous MSP measurements (Strelnikova et al., 2009) assuming a MSP mass density of $2 \mathrm{~g} \mathrm{~cm}^{-3}$, right panel: filtered neutral, positive and negative MSP densities (dashed lines) compared to the original MSP densities and ECOMA-1 data.

This is the reason why the densities of negative and positive MSP are similar there, namely, that the equal densities of positive and negative ions and their similar mean ion masses in this region lead to similar capture rates by MSP (see Fig. 4 and Eqs. 2 and 4).

\subsection{Comparison with experiments}

In this section we compare our modelled MSP densities with the Faraday cup measurements on rockets. A direct comparison is not reasonable, since in situ measurements with Faraday cups tend to give a biased representation of the MSP density abundant in the atmosphere. During rocket flights the ensemble of MSP that can enter a Faraday cup is different from the real MSP ensemble. Aerodynamical effects filter the MSP that can reach the Faraday cup's electrode and create a current at the electrometer. The shock front which evolves around the payload prevents small particles from entering the detector (e.g. Horanyi et al., 1999; Rapp et al., 2005). Hedin et al. (2007) have derived from Direct Simulation Monte Carlo calculations around the rocket payload a distinct MSP radius that can reach a Faraday cup electrode for different altitudes. It has to be noted, that this filter curve depends on the altitude-dependent rocket speed and the geometry of the particular detector. This method has been used also by Strelnikova et al. (2009) to compare with the Faraday cup measurements for the ECOMA-1 flight. This particular filter curve is shown in Fig. 8 (left panel) and is used in this study. Therefore we can only compare our analysis with the ECOMA-1 data and to a certain extent with the other ECOMA flights, but not with different experimental 
setups. Note however, that the MASS experiment is designed to avoid aerodynamical filtering which can be seen in Fig. 1 (green line), i.e. the measured MSP density does not have a sharp edge below $\sim 78 \mathrm{~km}$ and can be compared to the unfiltered modeled data.

This filter function has been applied to the MSP densities derived by our model. By doing so we can achieve results that are comparable to measured MSP charge number densities. These filtered MSP densities are shown in Fig. 8 (right panel) together with the Faraday cup data from the ECOMA-1 flight. Please note that neutral MSP cannot be measured by a Faraday cup, we only show filtered neutral MSP densities for comparison.

It is obvious that the density peak lies in the altitude region 80-95 km where Faraday cups also measure peak densities. While the unfiltered model data shows a clear excess of the neutral MSP particles compared to the charged fraction, the filtered data show similar number densities of negatively charged MSP and neutral MSP. This can be explained by the fact that the smaller MSP, which are aerodynamically prevented from entering the Faraday cup detector, are unlikely to be charged. Above $90 \mathrm{~km}$ the filtered negative MSP even outnumber the neutral MSP. That can be explained by the fact that a larger fraction of MSP with sizes above $1 \mathrm{~nm}$ are charged negatively rather than being neutral.

Below $78 \mathrm{~km}$ the filtered negative and positive MSP densities are equal. This may contribute to the frequent observations of a very sharp lower boundary of charged MSP layers as seen in Fig. 1, since Faraday cups measure integrally negative and positive MSP density which cancels out on the electrode. However, the main effect here is the steep increase of detectable MSP sizes as seen in Fig. 8.

By directly comparing the ECOMA-1 data with our filtered MSP density we find a good agreement in all altitudes. The measured profile fits moderately to the filtered modelled data; even the peaks of the modeled and measured maximal negative MSP density match at $87 \mathrm{~km}$, although the model overestimates the negative MSP density when comparing it to the measured density at the peak altitude. In the altitudes above and below $87 \mathrm{~km}$, the model seems to overestimate the measured number density of negatively charged smoke. However, in general it can be said that there is a reasonable qualitative agreement between the modeled negative MSP densities and the in situ observations, especially for the ECOMA experiments.

\subsection{Analysis of dominant plasma reactions}

Now we concentrate on the influence of MSP on the plasma densities. To investigate this point, we performed another model run with identical initial condition, except that the MSP density has been set to zero. The reaction scheme of the model run without MSP is reduced, i.e. reactions concerning MSP are excluded. The remaining reactions are characterized by $k_{1}^{\mathrm{S}}-k_{5}^{\mathrm{S}}$. The comparison between the model run with and

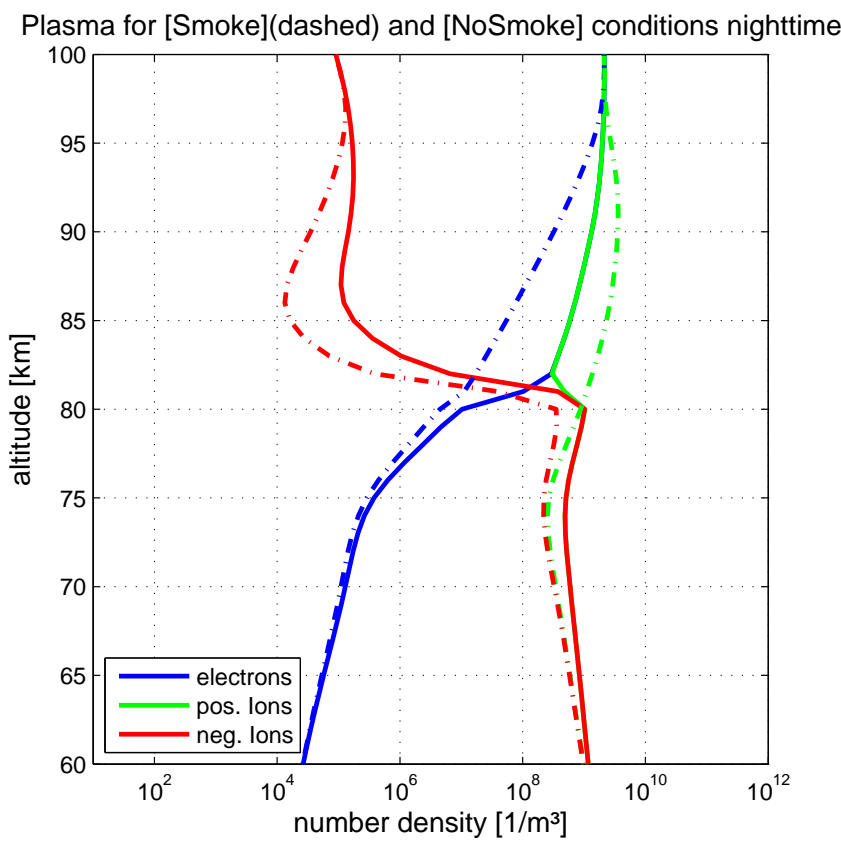

Fig. 9. Height profiles of the plasma densities, for a model run with MSP (dashed lines) and without MSP (solid lines).

without MSP directly visualizes the influence of MSP on the D-region plasma and is shown in Fig. 9. The effect, suggested by Friedrich et al. (2012), that MSP act as an effective electron sink between 80 and $95 \mathrm{~km}$ is clearly reproduced by this simple ionospheric model. In addition, there are also unexpected differences in the ion densities between the model run with and without MSP. In the same altitude region where a significant electron density loss is observed, the MSP model results show a reduction of the negative ion density and an enhancement in the positive ion density. Below $80 \mathrm{~km}$ the situation changes somewhat. Here we find a reduction of all three plasma constituents due to the presence of MSP.

In the following, these changes in the charge balance (due to the presence of MSP) are further analyzed by considering the production and loss processes in the rate equations for each plasma constituent. The reaction rates for electrons are shown in Fig. 10, for negative ions in Fig. 11, and for positive ions in Fig. 12. In all three figures we show the reaction rates of the model run with MSP (dashed lines) and without MSP (solid lines) together in one graph. Note that the reaction rates which represent the same processes in both model runs have the same color.

Figure 10 shows the modeled reaction rates for electron production and loss. Without MSP the main production processes of electrons are electron-ion pair production and the electron detachment from negative ions. This is balanced by electron attachment to neutrals and electron-positive ion dissociative recombination above $80 \mathrm{~km}$. Below $80 \mathrm{~km}$, the production is completely balanced by electron attachment to neutrals. Certainly the electron-ion pair production rate $k_{1}^{\mathrm{S}}$, 

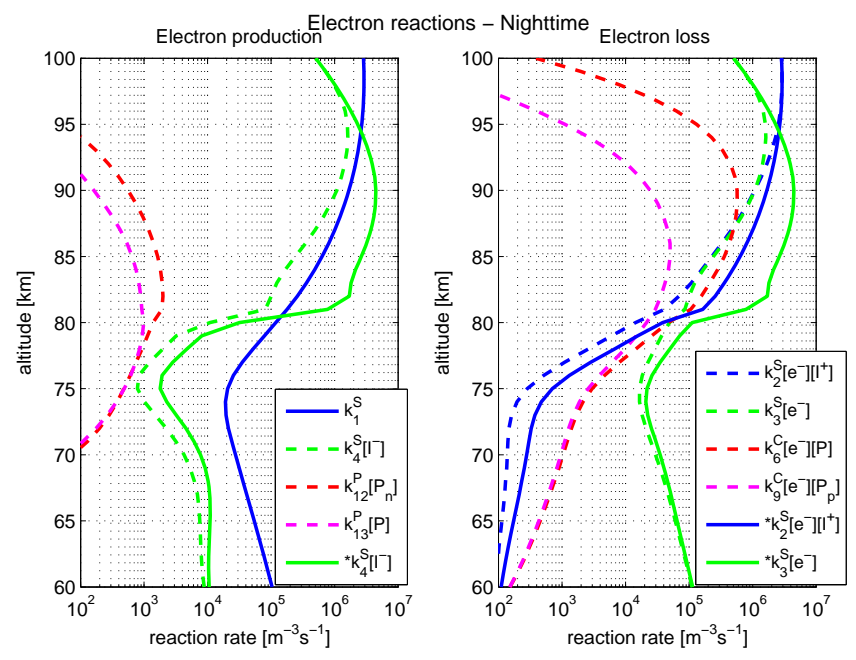

Fig. 10. Altitude profiles of electron production and loss rates. Dashed lines show results of the model run with MSP, solid lines show results of the model run without MSP, see also Eq. 9.

due to ionization, is independent of the presence of MSP. As stated above the MSP photo reactions are not very effective during the nighttime and therefore only few electrons are produced by these processes. The reduced electron density due to the presence of MSP accounts for the reduced negative ion density at the same time. Because of that, attachment of electrons to neutrals is reduced and at the same time the detachment process from negative ions is reduced. Below $80 \mathrm{~km}$ MSP do not have a significant influence on the electron processes anymore. The dominant electron sink in the altitude above $80 \mathrm{~km}$ is the electron capture by neutral $\operatorname{MSP}\left(k_{6}^{\mathrm{C}}\left[e^{-}\right][P]\right)$, while the production of electrons is dominated by the ionization $k_{1}^{\mathrm{S}}$. Without MSP presence, the dominant sinks and sources of electrons are the electron attachment to neutrals and the electron detachment from neutrals at altitudes below $80 \mathrm{~km}$.

The situation for negative ions is different although their existence is certainly coupled to the ambient electrons (see Fig. 11). There is a lack of negative ions above $80 \mathrm{~km}$ due to the reduced electron attachment. The density of negative ions is small compared to all other model components in that altitude region. Below $80 \mathrm{~km}$ the importance of negative ions grows and the presence of MSP leads to a decrease in negative ions there. While the production of negative ions are similar for both modeled cases, the loss processes are different. The capture of negative ions by MSP is more important than ion-ion recombination in that altitude region. The dominant sinks for negative ions are their capture by neutral and positively charged $\operatorname{MSP}\left(k_{10}^{\mathrm{C}}[P]\left[I^{-}\right], k_{11}^{\mathrm{C}}\left[P_{\mathrm{p}}\right]\left[I^{-}\right]\right)$. In the case of MSP absence, ion-ion recombination dominates the reduction of negative ions.

In the end we discuss the influence of MSP on the positive ion density (see Fig. 12). The considerable increase of

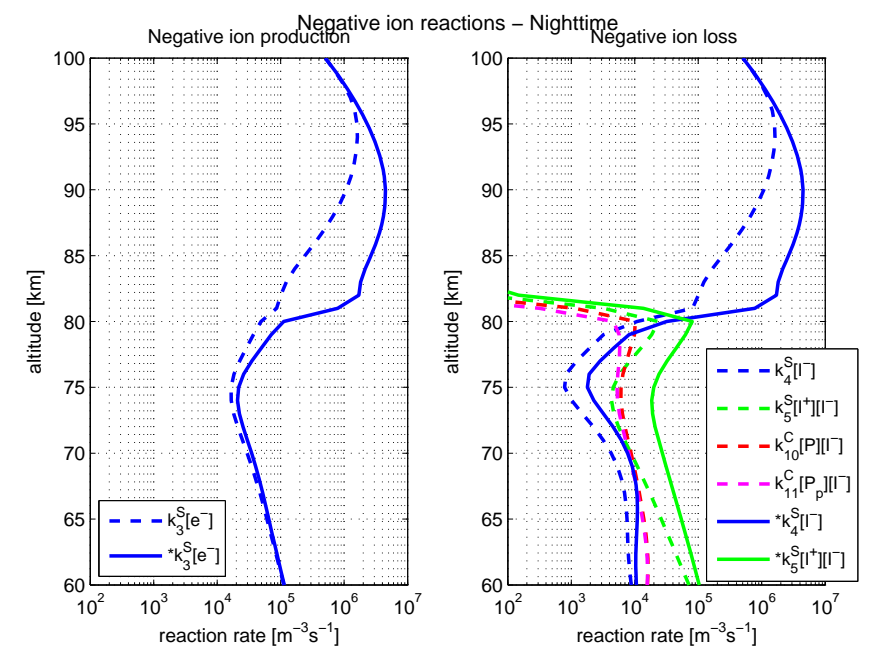

Fig. 11. As in Fig. 10, but for processes involving negative ions, see also Eq. (11).
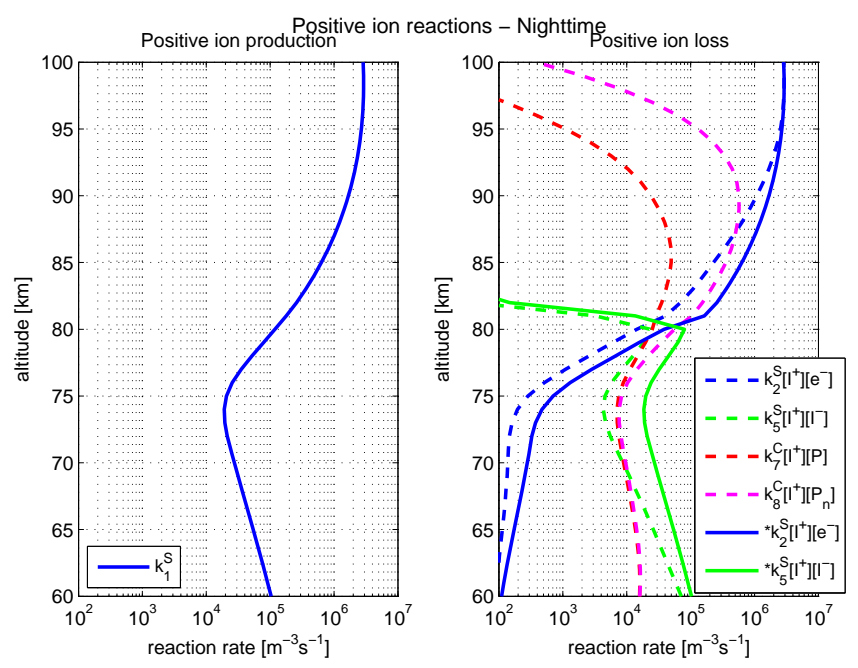

Fig. 12. As in Fig. 10, but for processes involving positive ions, see also Eq. 10.

the positive ion density in the presence of MSP is an effect that has not been explicitly discussed for a MSP environment before. We note that ion enhancements have been discussed in Rapp and Lübken (2001) who, however, focussed on ice particle charging effects in the polar summer mesosphere. The model runs with and without MSP presence are easier to compare for the positive ion densities, since their production is given by the ionization rate $k_{1}^{\mathrm{S}}$, which is not affected by MSP. Therefore we may concentrate on the loss processes only. There are two reactions that are related to the positive ion loss for both model runs. These are the dissociative recombination with electrons, which is important above $80 \mathrm{~km}$, and the ion-ion recombination, which is significant below $80 \mathrm{~km}$. It is obvious that both recombination processes are severely attenuated due to the presence of MSP. But the 
difference to the electrons and negative ions is that this attenuation leads to an increase of positive ions above $80 \mathrm{~km}$ and a reduction below $80 \mathrm{~km}$. The dissociative recombination with electrons is reduced due to the lack of electrons above $80 \mathrm{~km}$, simultaneously the positive-ion capture of neutral MSP is important here. The reason for additional positive ions in the presence of MSP is the scavenging of electrons by MSP, which leads to the reduction of the dissociative recombination with electrons. This reduced recombination causes a gain of positive ions. Below $80 \mathrm{~km}$ we have the same situation as for the negative ions, i.e. additional loss processes due to positive-ion capture by MSP lead to a reduced density. In all, the dominant positive ion sinks are the positive-ion capture by positive MSP and neutral MSP (below $80 \mathrm{~km}$ only). Without the presence of MSP main sinks are the dissociative recombination with electrons (above $80 \mathrm{~km}$ ) and the ion ion recombination (below $80 \mathrm{~km}$ ).

\section{Conclusions}

We have investigated the influence of MSP on the charge balance in the D-region ionosphere. Both in situ measurements and a one-dimensional ionospheric model were used to show a clear impact of MSP on the ionospheric composition of the D-region. As a major conclusion we may state that MSP are active charge carriers and are in fact important players in the charge balance of the D-region ionosphere.

The rocket-borne in situ measurements of electron and positive ion density show a distinct difference from charge neutrality between 80 and $95 \mathrm{~km}$. This difference can be explained by the ambient negatively charged MSP measured simultaneously with a Faraday cup. We addressed the influence of MSP on the D-region charge balance in a simplified ionospheric model with six components, i.e. electrons, positive and negative ions and neutral and charged MSP. Plasma captured by MSP and photo reaction of MSP have been included in the reaction scheme, together with the standard ionospheric processes, e.g. ion-ion recombination etc. The model results point in the same direction as the experimental findings, namely that MSP play an important role in the charge balance of the D-region by capturing electrons and ions. By applying a filter function, which simulates the aerodynamical filtering of particles by the shock front around the Faraday cup, to the modelled MSP densities, we get particle densities in good general agreement with the experimental data, especially given the many uncertainties involved in both experiment and modelling. The model shows that the capture of plasma constituents by MSP is a dominant process. The model study also revealed that $80 \mathrm{~km}$ is a crucial boundary for the different capture processes. The electrons are captured very effectively by neutral MSP only above $80 \mathrm{~km}$, while negative ions are captured by positive MSP and neutral MSP below $80 \mathrm{~km}$. The capture of positive ions by MSP is an important process in the complete altitude range between 60 and $100 \mathrm{~km}$ and accounts for a fraction of positively charged MSP.

The model study revealed an increase of positive ions above $80 \mathrm{~km}$ in the presence of MSP. This increase has also been discussed by Rapp and Lübken (2001) in an environment of ice particles. So far we have not yet considered which influence MSP have on the composition of positive and negative ions (if any). By implementing MSP into the full ion-chemistry of the SIC model, we plan to identify such conceivable effects on the composition. In addition, future studies will also focus on MSP effects on the charge balance during daytime conditions. This will require close collaboration with lab experiments due to large uncertainties inherent in MSP-material dependencies on corresponding photoelectrical properties.

Acknowledgement. The service charges for this open access publication have been covered by a Research Centre of the Helmholtz Association.

Topical Editor C. Jacobi thanks M. Friedrich and L. Megner for their help in evaluating this paper.

\section{References}

Amyx, K., Sternovsky, Z., Knappmiller, S., Robertson, S., Horanyi, M., and Gumbel, J.: In-situ measurement of smoke particles in the wintertime polar mesophere between 80 and $85 \mathrm{~km}$ altitude, J. Atmos. Sol.-Terr. Phy., 70, 61-70, doi:10.1016/j.jastp.2007.09.013, 2008.

Arijs, E., Nevejans, D., and Ingels, J.: Stratospheric positive ion composition measurements and acetonitrile detection: a consistent picture?, Int. J. Mass Spectrom., 81, 15-31, 1987.

Barjatya, A. and Swenson, C. M.: Observations of triboelectric charging effects on Langmuir-type probes in dusty plasma, J. Geophys. Res., 111, A10302, doi:10.1029/2006JA011806, 2006.

Ceplecha, Z., Borovička, J., Elford, W. G., ReVelle, D. O., Hawkes, R. L., Porubčan, V., and Šimek, M.: Meteor phenomena and bodies, Space Sci. Rev., 84, 327-471, 1998.

Eidhammer, T. and Havnes, O.: Size dependence of the mesospheric dust temperature and its influence on the noctilucent clouds and polar mesosphere summer echo phenomena, J. Geophys. Res., 106, 24831-24841, 2001.

Enell, C.-F., Hedin, J., Stegman, J., Witt, G., Friedrich, M., Singer, W., Baumgarten, G., Kaifler, B., Hoppe, U.-P., Gustavsson, B., Brändström, U., Khaplanov, M., Kero, A., Ulich, T., and Turunen, E.: The Hotel Payload 2 campaign: Overview of NO, O and electron density measurements in the upper mesosphere and lower thermosphere, J. Atmos. Sol.-Terr. Phy., 73, 2228-2236, doi:10.1016/j.jastp.2011.01.001, 2011.

Fentzke, J. T., Janches, D., Strelnikova, I., and Rapp, M.: Meteoric smoke particle properties derived using dual-beam Arecibo UHF observation of D-region spectra during different seasons, J. Atmos. Sol.-Terr. Phy., 71, 1982-1991, 2009.

Fowler, R. H. and Nordheim, L.: Electron Emission in Intense Electric Fields, Roy. Soc. London Proc. Ser. A, 119, 173-181, doi:10.1098/rspa.1928.0091, 1928. 
Friedrich, M. and Rapp, M.: News from the Lower Ionosphere: A Review of Recent Developments, Surv. Geophys., 30, 525-559, 2009.

Friedrich, M., Rapp, M., Blix, T., Hoppe, U.-P., Torkar, K., Robertson, S., Dickson, S., and Lynch, K.: Electron loss and meteoric dust in the mesophere, Ann. Geophys., 30, 1495-1501, doi:10.5194/angeo-30-1495-2012, 2012.

Friedrich, M., Torkar, K. M., Hoppe, U.-P., Bekkeng, T.-A., Barjatya, A., and Rapp, M.: Multi-instrument comparisons of Dregion plasma measurements, Ann. Geophys., 31, 135-144, doi:10.5194/angeo-31-135-2013, 2013.

Gelinas, L. J., Lynch, K. A., Kelley, M. C., Collins, S., Baker, S., Zhou, Q., and Friedman, J. S.: First observation of meteoric charged dust in the tropical mesosphere, Geophys. Res. Lett., 25, 4047-4050, 1998.

Havnes, O., Trøim, J., Blix, T., Mortensen, W., Næsheim, L., Thrane, E., and Tønnesen, T.: First detection of charged dust particles in the Earth's mesosphere, J. Geophys. Res., 101, 1083910847, 1996.

Havnes, O., La Hoz, C., Rietveld, M. T., Kassa, M., Baroni, G., and Biebricher, A.: Dust charging and density conditions deduced from observations of PMWE modulated by artificial electron heating, J. Geophys. Res., 116, D24203, doi:10.1029/2011JD016411, 2011.

Hedin, A. E.: Extension of the MSIS thermosphere model into the middle and lower atmosphere, J. Geophys. Res., 96, 1159-1172, 1991.

Hedin, J., Gumbel, J., and Rapp, M.: On the efficiency of rocketborne particle detection in the mesosphere, Atmos. Chem. Phys., 7, 3701-3711, doi:10.5194/acp-7-3701-2007, 2007.

Hervig, M. E., Gordley, L. L., Deaver, L. E., Siskind, D. E., Stevens, M. H., Russell, J. M., Bailey, S. M., Megner, L., and Bardeen, C. G.: First Satellite Observations of Meteoric Smoke in the Middle Atmosphere, Geophys. Res. Lett., 36, L18805, doi:10.1029/2009GL039737, 2009.

Hervig, M. E., Deaver, L. E., Bardeen, C. G., Russell III, J. M., Bailey, S. M., and Gordley, L. L.: The content and composition of meteoric smoke in mesospheric ice particles from SOFIE observations, J. Atmos. Sol.-Terr. Phy., 84-85, 1-6, doi:10.1016/j.jastp.2012.04.005, 2012.

Horanyi, M., Gumbel, J., Witt, G., and Robertson, S.: Simulation of rocket-borne particle measurements in the mesosphere, Geophys. Res. Lett., 26, 1537-1540, doi:10.1029/1999GL900298, 1999.

Horanyi, M., Robertson, S., Smiley, B., Gumbel, J., Witt, G., and Walch, B.: Rocket-borne mesospheric measurement of heavy charge carriers, Geophys. Res. Lett., 26, 1537-1540, doi:10.1029/2000GL011433, 2000.

Hunten, D. M., Turco, R. P., and Toon, O. B.: Smoke and Dust Particles of Meteoric Origin in the Mesosphere and Stratosphere, J. Atmos. Sci., 37, 1342-1357, 1980.

Lynch, K. A., Gelinas, L. J., Kelley, M. C., Collins, R. L., Widholm, M., Rau, D., MacDonald, E., Liu, Y., Ulwick, J., and Mace, P.: Multiple sounding rocket observations of charged dust in the polar winter mesosphere, J. Geophys. Res., 110, A03302, doi:10.1029/2004JA010502, 2005

Mechtly, E. A., Bowhill, S. A., Smith, L. G., and Knoebel, H. W.: Lower ionosphere electron concentration and collision frequency from rocket measurements of Faraday rotation, differential ab- sorption, and probe current, J. Geophys. Res., 72, 5239-5245, 1967.

Megner, L. and Gumbel, J.: Charged meteoric particles as ice nuclei in the mesosphere: Part 2 A feasibility study, J. Atmos. Sol.-Terr. Phy., 71, 1236-1244, doi:10.1016/j.jastp.2009.05.002, 2009.

Megner, L., Rapp, M., and Gumbel, J.: Distribution of meteoric smoke - sensitivity to microphysical properties and atmospheric conditions, Atmos. Chem. Phys., 6, 4415-4426, doi:10.5194/acp-6-4415-2006, 2006.

Megner, L., Siskind, D. E., Rapp, M., and Gumbel, J.: Global and temporal distribution of meteoric smoke: A twodimensional simulation study, J. Geophys. Res., 113, D03202, doi:10.1029/2007JD009054, 2008.

Meier, R.: Ultraviolet spectroscopy and remote sensing of the upper atmosphere, Space Sci. Rev., 58, 1-185, doi:10.1007/BF01206000, 1991.

Natanson, G. L.: On the theory of the charging of atmospheric aerosol particles as a result of capture of gas ions, Sov. Phys. Tech. Phys., 5, 538-551, 1960.

Rapp, M.: Capture rates of electrons and positive ions by mesospheric aerosol particles, J. Aerosol Sci., 31, 1367-1369, 2000.

Rapp, M.: Charging of mesospheric aerosol particles: the role of photodetachment and photoionization from meteoric smoke and ice particles, Ann. Geophys., 27, 2417-2422, doi:10.5194/angeo-27-2417-2009, 2009.

Rapp, M. and Lübken, F.-J.: Modelling of particle charging in the polar summer mesosphere: Part 1-General results, J. Atmos. Sol.Terr. Phy., 63, 759-770, 2001.

Rapp, M. and Lübken, F.-J.: Polar mesosphere summer echoes (PMSE): Review of observations and current understanding, Atmos. Chem. Phys., 4, 2601-2633, doi:10.5194/acp-4-2601-2004, 2004.

Rapp, M. and Strelnikova, I.: Measurements of meteor smoke particles during the ECOMA-2006 campaign: 1. Particle detection by active photoionization, J. Atmos. Sol.-Terr. Phy., 71, 477-485, doi:10.1016/j.jastp.2008.06.002, 2009.

Rapp, M. and Thomas, G. E.: Modeling the microphysics of mesospheric ice particles: Assessment of current capabilities and basic sensitivities, J. Atmos. Sol.-Terr. Phy., 68, 715-744, doi:10.1016/j.jastp.2005.10.015, 2006.

Rapp, M., Hedin, J., Strelnikova, I., Friedrich, M., Gumbel, J., and Lübken, F.-J.: Observations of positively charged nanoparticles in the nighttime polar mesosphere, Geophys. Res. Lett., 32, L223821, doi:10.1029/2005GL024676, 2005.

Rapp, M., Strelnikova, I., and Gumbel, J.: Meteoric smoke particles: Evidence from rocket and radar techniques, Adv. Space Res., 40, 809-817, doi:10.1016/j.asr.2006.11.021, 2007.

Rapp, M., Strelnikova, I., Strelnikov, B., Hoffmann, P., Friedrich, M., Gumbel, J., Megner, L., Hoppe, U.-H., Robertson, S., Knappmiller, S., Wolff, M., and Marsh, D. R.: Rocket-borne in situ measurements of meteor smoke: Charging properties and implications for seasonal variation, J. Geophys. Res., 115, D00I16, doi:10.1029/2009JD012725, 2010.

Rapp, M., Strelnikova, I., Strelnikov, B., Friedrich, M., Gumbel, J., Hoppe, U.-P., Blix, T., Havnes, O., Bracikowski, P., Lynch, K., and Knappmiller, S.: Aeronomy of the Earth's Atmosphere and Ionosphere, Chap. Microphysical Properties of Mesospheric Aerosols: An Overview of in situ Results from the ECOMAProjects, 67-74, Springer Science+Business Media B.V., 2011. 
Rapp, M., Plane, J. M. C., Strelnikov, B., Stober, G., Ernst, S., Hedin, J., Friedrich, M., and Hoppe, U.-P.: In situ observations of meteor smoke particles (MSP) during the Geminids 2010: constraints on MSP size, work function and composition, Ann. Geophys., 30, 1661-1673, doi:10.5194/angeo-30-1661-2012, 2012.

Robertson, S., Horanyi, M., Knappmiller, S., Sternovsky, Z., Holzworth, R., Shimogawa, M., Friedrich, M., Torkar, K., Gumbel, J., Megner, L., Baumgarten, G., Latteck, R., Rapp, M., Hoppe, U.-P., and Hervig, M. E.: Mass analysis of charged aerosol particles in NLC and PMSE during the ECOMA/MASS campaign, Ann. Geophys., 27, 1213-1232, doi:10.5194/angeo-271213-2009, 2009.

Robertson, S., Dickson, S., Horanyi, M., Sternovsky, Z., Friedrich, M., Janchez, D., Megner, L., and Williams, B.: Detection of Meteoric Smoke Particles in the Mesosphere by a Rocket-borne Mass Spectrometer, J. Atmos. Sol.-Terr. Phy., doi:10.1016/j.jastp.2013.07.007, in press, 2013.

Rosinski, J. and Snow, R. H.: Secondary particulate matter from meteor vapors, J. Meteorol., 18, 736-745, 1961.

Russel, J. P., Ward, W. E., Lowe, R. P., Roble, R. G., Shepherd, G. G., and Solheim, B.: Atomic oxygen profiles (80 to $115 \mathrm{~km}$ ) derived from Wind Imaging Interferometer/Upper Atmospheric Research Satellite measurements of the hydroxyl and greenline airglow: Local time-latitude dependence, J. Geophys. Res., 110, D15305, doi:10.1029/2003JD003454, 2005.

Schmidt-Ott, A., Schurtenberger, P., and Siegmann, H. C.: Enormous Yield of Photoelectrons from Small Particles, Phys. Rev. Lett., 45, 1284-1286, 1980.

Schulte, P. and Arnold, F.: Detection of upper atmospheric negatively charged microclusters by a rocket-borne mass spectrometer, Geophys. Res. Lett., 19, 2297-2300, 1992.
Stober, G., Schult, C., Baumann, C., Latteck, R., and Rapp, M.: The Geminid meteor shower during the ECOMA sounding rocket campaign: specular and head echo radar observations, Ann. Geophys., 31, 473-487, doi:10.5194/angeo-31-473-2013, 2013.

Strelnikova, I., Rapp, M., Strelnikov, B., Baumgarten, G., Brattli, A., Svenes, K., Hoppe, U.-P., Friedrich, M., Gumbel, J., and Williams, B. P.: Measurements of meteor smoke particles during the ECOMA-2006 capaign: 2. Results, J. Atmos. Sol.-Terr. Phy., 71, 486-496, doi:10.1016/j.jastp.2008.07.011, 2009.

Tobiska, W. K., Woods, T., Eparvier, F., Viereck, R., Floyd, L., Bouwer, D., Rottman, G., and White, O.: The SOLAR2000 empirical solar irradiance model and forecast tool, J. Atmos. Sol.Terr. Phy., 62, 1233-1250, 2000.

Triaud, A. H.: n-k data for $\mathrm{Fe}_{2} \mathrm{O}_{3}$, Website, available at:http:// www.astro.uni-jena.de/Laboratory/OCDB/oxsul.html (2013-1113), 2013.

Turco, R. P., Toon, O. B., Keesee, R. C. W. R. G., and Hollenbach, D.: Noctilucent clouds: simulation studies of their genesis, properties and global influences, Planet Space Sci., 3, 1147-1181, 1982.

Turunen, E., Matveinen, H., Tolvanen, J., and Ranta, H.: STEP Handbook of Ionospheric Models, Chap. D-region ion chemistry model, 1-25, SCOSTEP Secretariat, 1996.

Viggiano, A. and Arnold, F.: Handbook of atmospheric electrodynamics, Vol. 1, Chap. Ion chemistry and composition of the atmosphere, CRC Press, 1995. 